\title{
Recharging prioritization method for the integration of electric vehicle fleets with the Smart Grid: an evolutionary computation approach
}

\author{
Juan Ignacio Guerrero, Antonio Parejo, Enrique Personal, Sebastián García, Javier A. Guerra, Carlos León \\ Department of Electronic Technology, Escuela Politecnica Superior \\ University of Seville, 41011, Seville, Spain
}

Email: juaguealo@us.es; aparejo@us.es; epersonal@us.es; sgarcia15@us.es; jgcoronado@us.es; cleon@us.es

\begin{abstract}
The recent advances on electric vehicles are accelerating their expansion across the world. Their advantages from the ecological point of view are positioning them as the future transport method. Despite of all their advantages, the recharging of these vehicles will raise difficulties from the point of view of power system planning due to their high-power demand. They can cause high consumption peaks over the system if many of them are charged simultaneously. Therefore, this problem must be solved for not to stop the expansion of electric vehicles. In this sense, this paper proposes the use of evolutionary computation methods for the planning of vehicle recharging as part of a complete platform based on virtual power plants. In this way, the integration between fleets and the grid can be achieved, reducing the peak power requirements. Different algorithms are described and compared here, showing their performance and computational cost.
\end{abstract}

Keywords-Smart grid; electric vehicle; vehicle-togrid; evolutionary computation.

\section{INTRODUCTION}

The combination of electric vehicle (EV) fleets and Smart Grids [1] are expected to be one of the best ways to reduce pollution and increase power efficiency in the future, substituting traditional vehicles moved by fossil fuels. Recent advances on battery technology and fast recharging methods [2] are reducing the gap between both vehicle types. Notwithstanding, the growing deployment of this type of vehicles has a big problem: the management of the power system is becoming more complex [3]. The reason is that EVs are literally "mobile loads", which demand high power in those points where they recharge the batteries. So, the distributed character of the power system will increase dramatically after the massive inclusion of electric vehicles. As an example, the effects of EV over low voltage network can be appreciated in [4]. Therefore, the whole power system must be prepared for this great change.

Many solutions have been studied to deal with this problem, e.g. the vehicle-to-grid technology (V2G), which is one of the most studied solutions. In [5], the authors present a multi-objective optimization strategy for the reduction of the gap between peak and valley loads applying a genetic algorithm. In [6], a synergy between photovoltaic (PV) generation and $\mathrm{EV}$ is presented to reduce voltage level fluctuations in the power system, mitigating the effects of PV power changes. The batteries of the EV are then used as regulation elements, avoiding the installation of extra stationary batteries in the grid.

The effects of EV over markets has also been studied by some researchers. K. Valentine et al. [7] present a study showing how EV charging and renewable generation can be affected at market level, and how they could be better integrated.

Other authors propose the use of specific smart grid frameworks and models to deal with the problem. For example, J. Romero-Ruiz et al. [8] present a model to reduce congestions in radial distribution networks where there are EVs and renewable generation. They consider both controlled EV and uncontrolled EV as part of the model. This solution, despite their good results, has the disadvantage of needing a huge knowledge of the objective network and its composition.

In this sense, other authors have taken a more "lowlevel" approach, centering on the information regarding a fleet of vehicles and the recharging stations. In [9], G. Hiermann et al. present a solution to the recharging time and location, considering routes, economics, and other factors.

Following this idea, the present paper proposes a charging prioritization methodology for electric vehicles. This concept, which was already presented by J.I. Guerrero et al. in [10], is explained more in detail and a new study case is also included. The objective of this methodology is to define a plan for the recharging of a fleet of vehicles, using the data of the routes they must 
cover along a specified period, the number of vehicles, the evolution of their state of charge (SoC), and other relevant information. The obtained solutions are optimized to avoid an overcharge of the network, which could happen if many vehicles want to charge at the same time. One of the innovations of the paper is the combination of evolutionary computation (where variations are introduced in the solutions in order to improve it on every cycle) and an architecture based on virtual power plants (VPP). The new study case presented here provides more results to appreciate the comparison between the different proposed algorithms.

Section 2 expose the proposed VPP architecture and its parts. Section 3 presents the different algorithms that are applied. The study case and its results are described in Section 4. Finally, Section 5 contains the conclusions.

\section{GENERAL VPP ARCHITECTURE}

The proposed prioritization method is part of a bigger platform that works in the scope of a Virtual Power Plant (VPP). The use of a VPP is justified because of their easy integration of heterogeneous electric systems (both generation and consumption) connected. In fact, VPPs are usually applied in this type of solutions by other researchers. F. Marra et al. [11] propose their use to provide regulating power reserves through EV. In [12], $\mathrm{M}$. Kolenc et al. investigates the use of VPP and OpenADR protocol, which is a popular standard oriented to demand response actions, for the management of EV recharge.

Following this idea, the different power system actors can share VPP information. The architecture, specifically detailed for the case of EV management, is as shown in Figure 1.

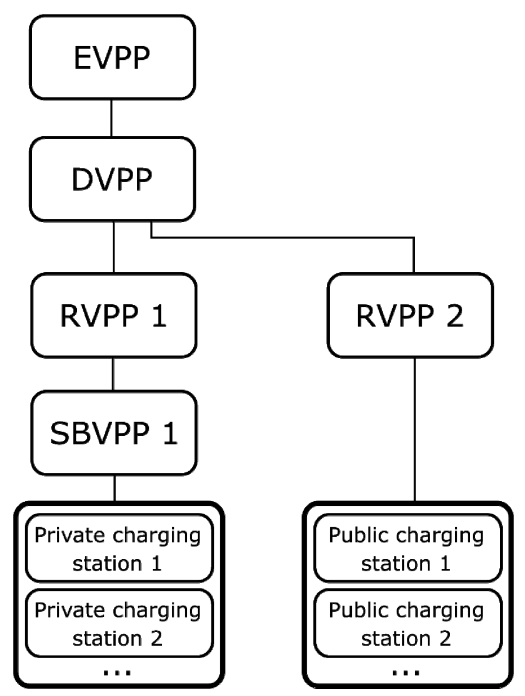

Fig. 1: Structure of the platform
The main elements are:

- Smart business VPP (SBVPP): the lowest level. Used directly by the company with a EV fleet.

- Distribution VPP (DVPP): uses information about retailers and charging stations.

- Retailer VPP (RVPP): it is used by the retailer, so it contains information about tariffs to be applied to dependent companies.

- Energy VPP (EVPP): the higher level. Integrates all the energy requirements of the lower levels of the grid.

As it is indicated, an VPP platform would be part of a company systems, performing the tasks of EV recharging management. The platform proposed here has the structure shown in the Figure 2, where the prioritization method can be observed.

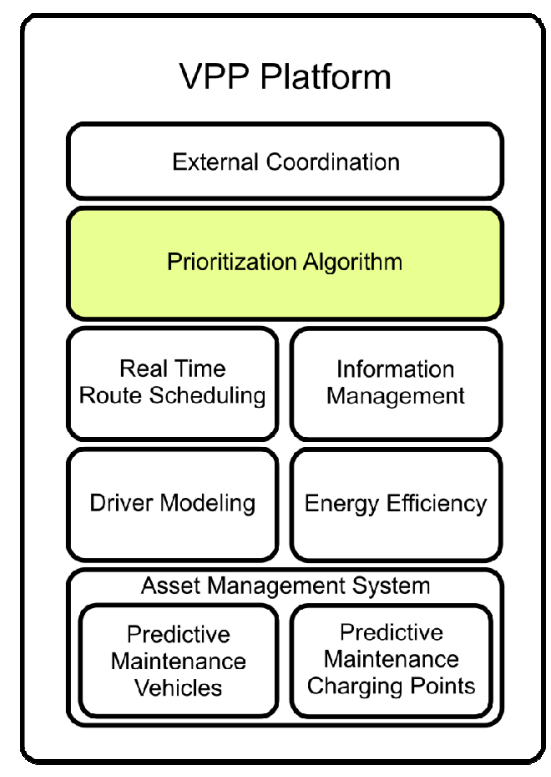

Fig. 2: Structure of the platform

The SBVPP platform (used in this proposal by companies that uses EV fleets) uses information relative to routes and drivers, as it was explained before. Using this information, some algorithms have been proposed and compared for getting the solution, which is the schedule of the complete routes and recharging points (and times of recharge) for every vehicle along the day.

It is important to note that the proposed algorithms are not only used by the SBVPP, but also for all the other mentioned VPP at higher levels. High level VPPs will apply their algorithms with the objective of modify the queues of the lower ones. Low level VPPs (SBVPP) apply the algorithms in order to send resource requests to other stations which are not under their control (when needed).

The platform is adapted to every element presented in the Figure 1. The complete platform (which is called Smart Business VPP, SBVPP) is used by EV companies. 
For EVPP, DVPP and RVPP, some unnecessary function blocks are disabled. For example, it would not have sense to keep the functions of driver modeling in the system DVPP. In the case of the distributor VPP, it does not need that information for the planning of power requirements neither.

\section{ALGORITHMS}

In this work, four types of algorithms have been applied in order to compare them. The criteria for this comparison is how fast they are able to reach a valid solution. A solution can be considered valid when it accomplishes all the route points required while keeping admissible battery levels for all the vehicles during their routes.

To check if a solution is valid or not the needed parameter is "solution validity" (fitness). This value expresses how good is a determinate solution for performing the set of routes for the day while maintaining a good battery level during that period, including the recharging places. In the case of a valid solution, this parameter will be equal to 1 .

The applied algorithms have been:

- Genetic algorithm (GA)

- Genetic algorithm with evolution control (GAEC) based on the evolution of the fitness curve.

- Particle swarm optimization (PSO)

- Hybrid algorithm. It is a combination of the mentioned algorithms over the architecture. This means that every type of VPP (which are EVPP, DVPP, RVPP and SBVPP) can use the most convenient algorithm of the three available (GA, GAEC or PSO).

The characteristics of these algorithms are as follows.

\section{A. Genetic algorithm (GA)}

In this algorithm, each VPP modules runs the proposed Genetic Algorithm, but of course each of them works with different information levels, as it was explained upper.

The GA is based on a generation of population, everyone from this population described a possible solution for the problem, in this case, a scenario of routing scheme. The crossover and mutation are operators which have a probability associated. The probability of crossover is greater than mutation operator.

However, the population selection is performed by means of another operator (called "selection operator"), which is generally based in an elitist approach. This means that the algorithm only selects the best individuals.

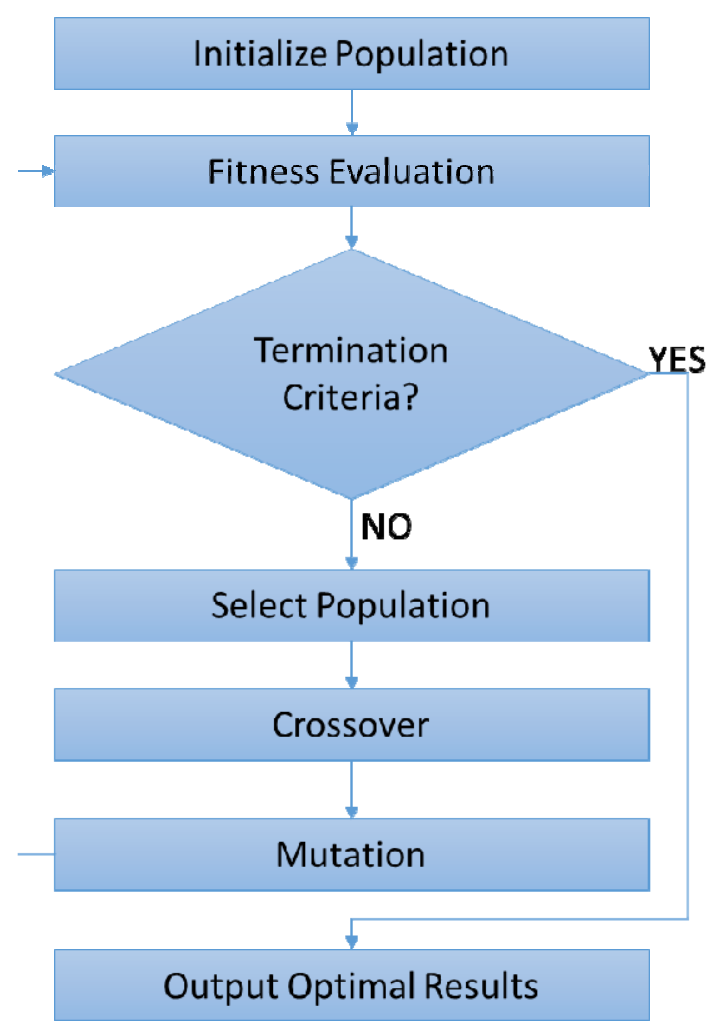

Fig. 3: General Flow Diagram for GA.

\section{B. Genetic algorithm with evolutionary control (GAEC)}

This algorithm is similar to GA (Fig. 3), the only difference is the associated probability of the Crossover and Mutation operator. This probability depends on the fitness curve. The probability of crossover operator is represented by the sine of angle from slope of fitness curve in the previous population, and the probability of mutation is associated with the cosine of this curve. So, in this case, when the fitness value increases a lot between different populations the probability of crossover is very high. However, when the difference of fitness value is very low the probability of crossover is low, and the mutation is very high. This variation avoids the problem of local optima. In this case, each VPP runs the GAEC with different types of information.

\section{Particle swarm optimization (PSO)}

In this algorithm, the possible solutions are established as a cloud of particles with certain position and velocity in the space, and after that each of them suffer certain changes in order to search for better solutions. The Fig. 4 shows the diagram flow of the PSO algorithm.

In this case, all VPPs are running a PSO algorithm. 


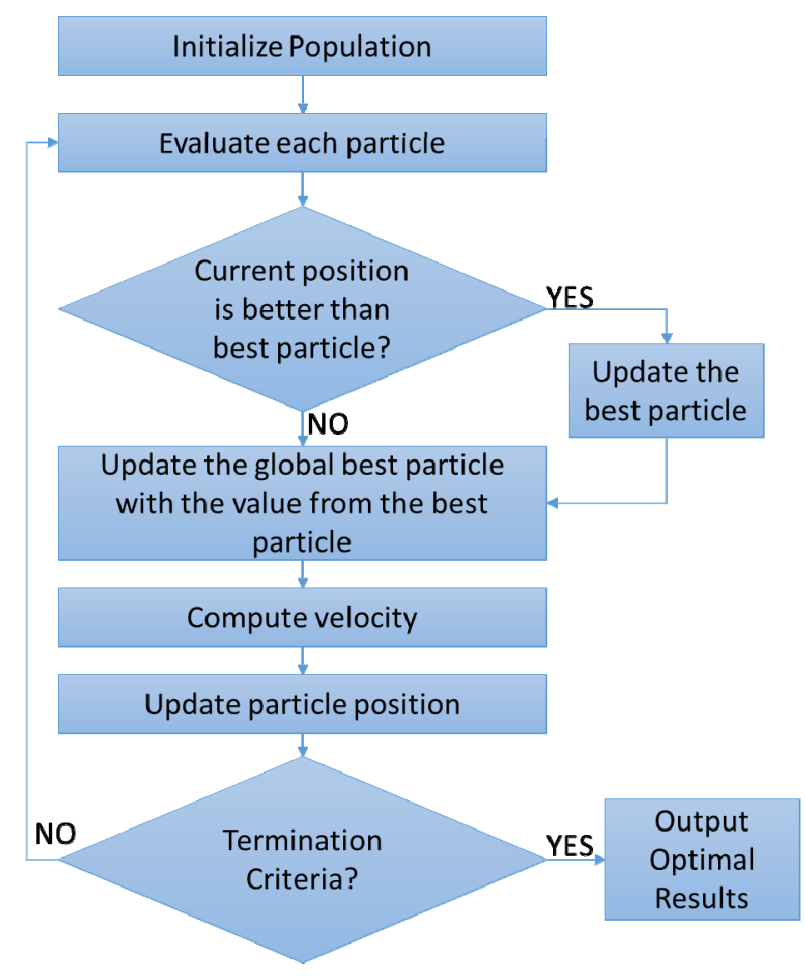

Fig. 4: General Flow Diagram for PSO algorithm.

\section{Hybrid approach (HA)}

The hybrid approach is based on running different algorithms in each VPPs. Of course, there are a lot of combinations for the application of every type of algorithm over every element in the system. The specific combination that has provided better results during the previous experiments will be applied, this comparison is out of scope of this paper. Therefore, the application of the hybrid approach is: in the SBVPP the PSO is run, while in the RVPP, DVPP, and EVPP the GAEC algorithm is applied.

\section{EXPERIMENT DESCRIPTION AND RESULTS}

The platform was tested using data generated from the information provided by a logistic and a transport company, including routes and other characteristics. This real information was processed to create a simulation scenario which is bigger and more complex than the real one. The simulation considers a greater number of available vehicles than the real fleet, and two different companies instead of one. In this way, a greater set of data is generated from the real available data source. The process considers the length of routes, number of stops, number of routes, etc. Several entities are created:

- Two smart business parks (A and B) with separate EV fleets. Company A (which owns 12 EVs) is a company in the logistics sector, and company B (which owns $18 \mathrm{EVs}$ ) is a company in the transport sector.

- Four public charging stations.

- Twelve private EVs (the private EVs are supposed to be totally charged at the beginning of the day).

The final platform is formed by several VPPs:

- Three retailers. Each of these retailers has a RVPP. One retailer has a supply contract with company $\mathrm{A}$, the other one with company $\mathrm{B}$, and the private vehicles are aleatory distributed between the three retailers.

- One power Distribution Company.

- An EMS is simulated and configured to randomly generate a power consumption command in the EVPP. Those commands are randomly fired.

- Companies A and B have both SBVPPs. The characteristics of these companies are listed in table 1.

Table 1. Characteristics of both companies with EV Fleets.

\begin{tabular}{|c|c|c|}
\hline Characteristics & Company A & Company B \\
\hline Number of routes & 400 & 600 \\
\hline Number of EVs & 12 & 18 \\
\hline Number of drivers & 9 & 10 \\
\hline $\begin{array}{l}\text { Number of charging } \\
\text { stations (private) }\end{array}$ & 2 & 2 \\
\hline $\begin{array}{l}\text { Number of charging } \\
\text { stations (shared) }\end{array}$ & 4 & 4 \\
\hline $\begin{array}{l}\text { Number of plugs by } \\
\text { charging station }\end{array}$ & 2 & 3 \\
\hline Power of charging & $1 x D C 50$ & $1 \times D C 50$ \\
\hline $\begin{array}{l}\text { stations (each charging } \\
\text { station) }\end{array}$ & $\begin{array}{c}\mathrm{kW} / 1 \mathrm{xAC} 43 \\
\mathrm{kVA}\end{array}$ & $\begin{array}{c}\mathrm{kW} / 2 \mathrm{xAC} 43 \\
\mathrm{kVA}\end{array}$ \\
\hline $\begin{array}{c}\text { Time of fast-charge in } \\
\text { external charging } \\
\text { stations (0 to } 80 \%)\end{array}$ & 30 minutes & 30 minutes \\
\hline
\end{tabular}

The described scenario for the simulations is shown in the Figure 5: 


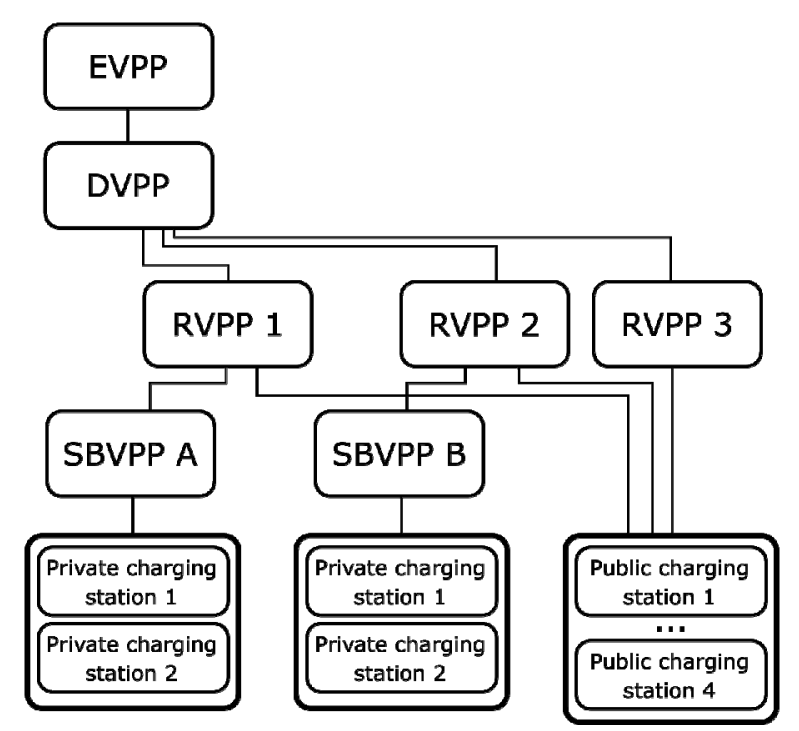

Fig. 5: Simulated scenario

The evaluation of the proposed solution is conducted in several scenarios:

- Using only evolutionary algorithms based on GA.

- Using only evolutionary algorithms based on GAEC.

- Using only evolutionary algorithms based on PSO.

- Hybrid solution.

The proposed solution is evaluated by checking three aspects, which are based in the number of generations or iterations that are performed to reach a solution in every case:

- Convergence time $\left(\mathrm{t}_{\mathrm{c}}\right)$. Time to reach a first solution from the initial moment. The convergence time is measured in number of iterations.

- Transient time $\left(t_{t}\right)$. Time to obtain a new solution when changes (events) occur in the conditions of the problem. This parameter is considered in this paper for every type of event separately. The transient time is measured in number of iterations.

- Average transient time $\left(t_{t a}\right)$. The average of $t_{t}$ for all events.

Those parameters can be observed in the Figure 6, where the system starts the calculation of valid solutions for every algorithm, and after some cycles a solution is reached (solution validity is equal to 1 ). After that, some events are also fired randomly. Those events cause the solution to be invalid, so new processing is made to return to a valid one.

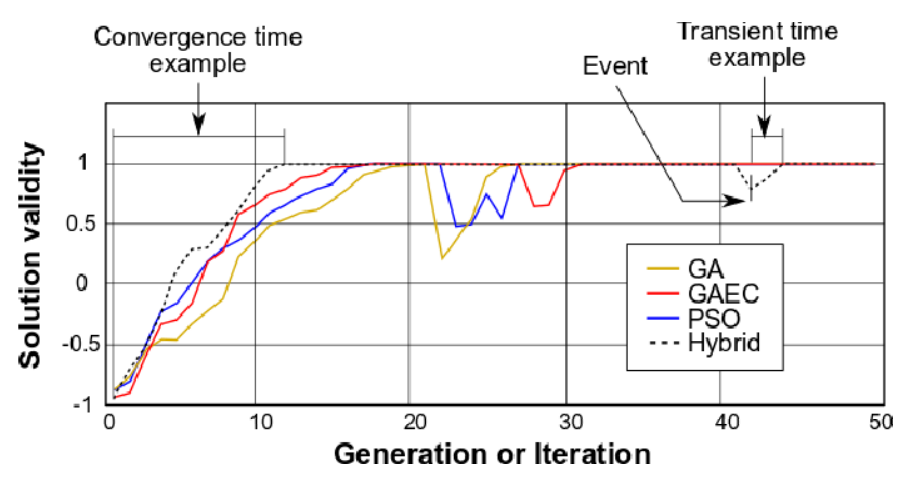

Fig. 6: Simulated scenario

In this case, the simulator randomly fired 25 events which takes effect in the scheduling:

- 5 events from EVPP.

- 5 events from SBVPP of Company A, to add 3 routes.

- 5 events from SBVPP of Company B, to add 3 routes.

- 5 events from SBVPP of Company A, to modify 2 routes.

- 5 events from SBVPP of Company B, to modify 2 routes.

The main objective of these events is the evaluation of average transient time, especially when a schedule change is needed, and the solution must be adapted to the new scenario. The delay due to communication between VPPs is not modeled in this experiment, because the platform is simulated in a software environment.

The results of simulations in terms of transient time $\left(t_{t}\right)$ for every algorithm in every type of event are represented here. Figure 7 represents times for EVPP event, Figure 8 contains similar data for events of route adding, and Figure 9 for events of route modification.

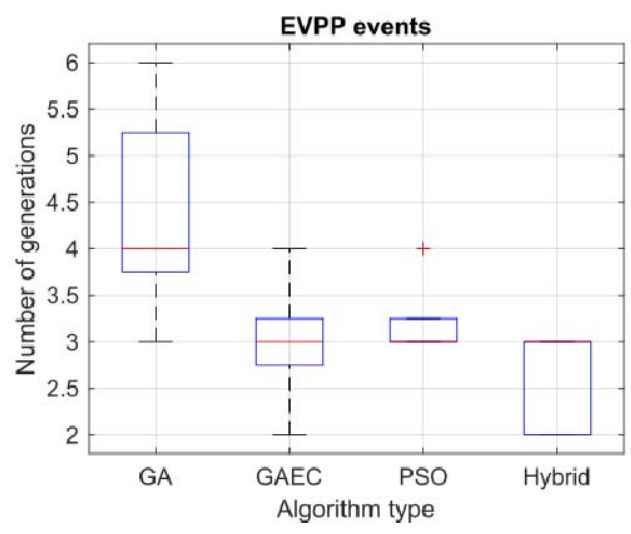

Fig. 7: Number of generations for EVPP events 


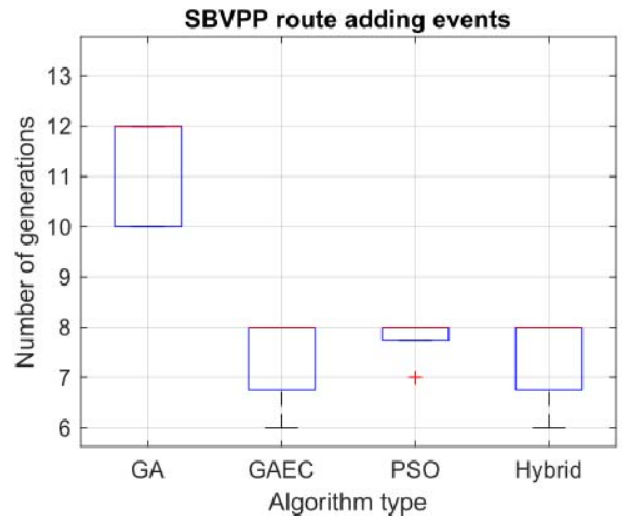

Fig. 8: Number of generations for SBVPP route adding events (for companies $\mathrm{A}$ and $\mathrm{B}$ )

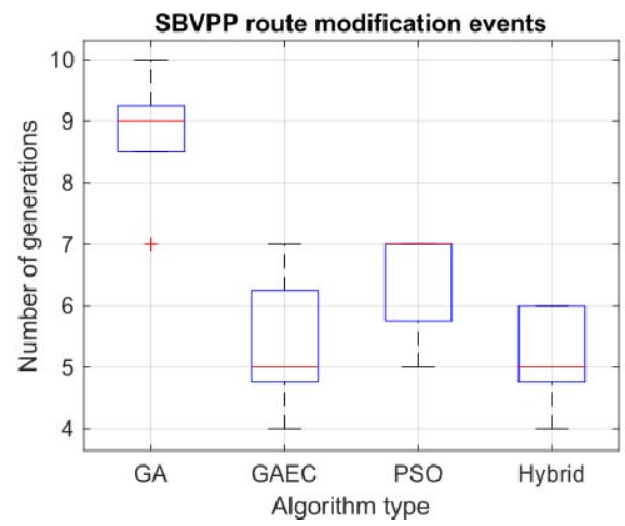

Fig. 9: Number of generations for SBVPP route modification events for company A

The global performance of all the applied algorithms can be described with the indicators $t_{c}$ and $t_{t a}$ which respectively reflects how fast the route is generated from the start of the computation, and how the schedule is corrected when a perturbance occurs (without distinguishing between different event types). The results are shown in Table 1.

TABLE 1: PERFORMANCE COMPARISON

\begin{tabular}{|c|c|c|}
\hline $\begin{array}{c}\text { Test } \\
\text { Scenarios }\end{array}$ & $\begin{array}{c}\mathbf{t}_{\mathrm{c}} \text { (number of } \\
\text { generations) }\end{array}$ & $\begin{array}{c}\mathbf{t}_{\text {ta }} \text { (number of } \\
\text { generations) }\end{array}$ \\
\hline Only GA & 19 & 4.88 \\
\hline Only GAEC & 16 & 3.16 \\
\hline Only PSO & 16 & 3.48 \\
\hline $\begin{array}{c}\text { Hybrid } \\
\text { Solution }\end{array}$ & 11 & 3.04 \\
\hline
\end{tabular}

As can be appreciated, the hybrid approach has the best results, reaching the initial solution in less generations than other approaches, and also minimizing the time to adapt the schedule after events. In hybrid method, the SBVPPs use the PSO algorithm, while the other VPPs uses GAEC.

\section{CONCLUSION}

The distributed power system provides many advantages, such as a better use of renewable energy thanks to Distributed Energy Resources (DER) and the expansion of the EV. Notwithstanding, this type of structure has associated a big increase in management complexity.

This paper proposes a system for the optimization of charging prioritization of $\mathrm{EV}$, which realizes the task of deciding where and when every vehicle should be charged to accomplish with the scheduled routes.

The simulation shows that a combination of genetic algorithms and PSO gives very good results. Moreover, their computational cost is very low. Therefore, it is possible to apply those algorithms in the proposed VPP platform in near-real time.

\section{ACKNOWLEDGMENT}

The authors would like to thank the Ministry of Science, Innovation and Universities, Government of Spain for the concession of the project "BIGDATA ANALITYCS E INSTRUMENTACION CYBERFISICA PARA SOPORTE DE OPERACIONES DE DISTRIBUCION EN LA SMARTGRID”, number RTI2018-094917-B-I00.

Antonio Parejo is supported by the scholarship "Formación de Profesorado Universitario" number FPU16/03522 granted by the Ministry of Education and Professional Formation.

\section{REFERENCES}

[1] M. Sanduleac, M. Eremia, L. Toma, and P. Borza, "Integrating the Electrical Vehicles in the Smart Grid through unbundled Smart Metering and multi-objective Virtual Power Plants," in IEEE PES Innovative Smart Grid Technologies Conference Europe, 2011.

[2] Y. Liu, Y. Zhu, and Y. Cui, "Challenges and opportunities towards fast-charging battery materials," Nature Energy, vol. 4 , no. 7, pp. 540-550, 2019.

[3] J. Hu, H. Morais, T. Sousa, and M. Lind, "Electric vehicle fleet management in smart grids: A review of services, optimization and control aspects," Renewable and Sustainable Energy Reviews, vol. 56, pp. 1207-1226, 2016.

[4] Y. Zou, J. Zhao, X. Gao, Y. Chen, and A. Tohidi, "Experimental results of electric vehicles effects on low voltage grids," Journal of Cleaner Production, vol. 255, 2020.

[5] Z. Huang, B. Fang, and J. Deng, "Multi-objective optimization strategy for distribution network considering V2G-enabled electric vehicles in building integrated energy system," Protection and Control of Modern Power Systems, vol. 5, no. 1, 2020.

[6] N. B. G. N. Brinkel, M. K. M. Gerritsma, T. A. T. AlSkaif, I. I. Lampropoulos, A. M. A. van Voorden, H. A. H. Fidder, and W. G. J. H. M. W. van Sark, "Impact of rapid PV fluctuations on power quality in the low-voltage grid and mitigation strategies using electric vehicles," International Journal of Electrical Power and Energy Systems, vol. 118, 2020. 
[7] K. Valentine, W. Temple, R. J. Thomas, and K. M. Zhang, "Relationship between wind power, electric vehicles and charger infrastructure in a two-settlement energy market," International Journal of Electrical Power \& Energy Systems, vol. 82, pp. 225-232, 2016.

[8] J. Romero-Ruiz, J. Pérez-Ruiz, S. Martin, J. A. Aguado, and S. D. la Torre, "Probabilistic congestion management using EVs in a smart grid with intermittent renewable generation," Electric Power Systems Research, vol. 137, pp. 155-162, 2016.

[9] G. Hiermann, J. Puchinger, S. Ropke, and R. F. Hartl, "The Electric Fleet Size and Mix Vehicle Routing Problem with Time Windows and Recharging Stations," European Journal of Operational Research, vol. 252, no. 3, pp. 995-1018, 2016.

[10] J. I. Guerrero, E. Personal, A. García, A. Parejo, F. Pérez, and C. León, "Distributed charging prioritization methodology based on evolutionary computation and virtual power plants to integrate electric vehicle fleets on smart grids," Energies, vol. 12, no. 12, 2019.

[11] F. Marra, D. Sacchetti, A. B. Pedersen, P. B. Andersen, C. Traholt, and E. Larsen, "Implementation of an Electric Vehicle test bed controlled by a Virtual Power Plant for contributing to regulating power reserves," in IEEE Power and Energy Society General Meeting, 2012.

[12] M. Kolenc, N. Ihle, C. Gutschi, P. Nemček, T. Breitkreuz, K. Gödderz, N. Suljanović, and M. Zajc, "Virtual power plant architecture using OpenADR 2.0b for dynamic charging of automated guided vehicles," International Journal of Electrical Power and Energy Systems, vol. 104, pp. 370-382, 2019. 